\title{
Hartmann colostomy with ligasure
}

\author{
Karahan $\mathrm{O}^{1}$, Okus $\mathrm{A}^{1}$, Eryilmaz $\mathrm{MA}^{1}$, Ay $\mathrm{S}^{1}$, Kilic $\mathrm{S}^{2}$, Sevinc $\mathrm{B}^{1}$ \\ Konya Training and Research Hospital General Surgery Clinic, Konya Egitim ve Arastirma, Meram, \\ Konya, Turkey.serdenay@yahoo.com
}

\begin{abstract}
Purpose: While LigaSure is commonly used for blood vessel closure, our aim was to research the effectiveness of using the latter tool for the purpose of closing intestines in rats.

Methods: Twenty Wistar albino rats were divided into two groups per 10 each. In Group 1, the sigmoid colon was cut from its middle and its distal was closed with 4/0 silk. In Group 2, on the other hand, the sigmoid coIon was divided from the middle with LigaSure LS1200 probe and its distal was closed with LigaSure. In both groups, the proximal sigmoid colon was entered by means of colostomy with $4 / 0$ silk to the left part of the abdomen. Operation durations, adhesion levels and explosion pressures were recorded. Tissue samples were taken for tissue hydroxyproline level.

Results: While the average duration of the operation was 25.7 minutes in Group 1, it was 18.8 minutes in Group 2 and the difference between them was significant in favour of LigaSure. $(p<0.001)$. Stump explosion pressure was $181.4(160-190) \mathrm{mmHg}$ in average in the suture group (Group 1), and $173.3(150-190) \mathrm{mmHg}$ in the LigaSure group (Group 2) and the difference between them was not statistically significant. Tissue hydroxyproline level was $123.6(13-232)$ in Group 1, and $123.3(32-216)$ in Group 2 and no significant difference was determined between the groups. Adhesion level between the groups was also similar.

Conclusions: This study experimentally shows that the duration of effective stump closure as part of Hartman colonostomy can be shortented with LigaSure (Tab. 1, Fig. 4, Ref. 12). Full Text in PDF www.elis.sk.

Key words: LigaSure, experimental study, hartmann colostomy, intestinal closure.
\end{abstract}

LigaSure vessel closure technology is a system providing permanent blood vessel wall fusion by denaturing the collagen and elastin in the blood vessel wall and transforming it into a haemostatic plug (1). It allows fast closure of tissues without performing dissection. It has been shown in studies that vessels which are closed with LigaSure are not opened at a pressure up to three times the normal systolic blood pressure at minimum (2).

It has been shown in the studies that closure with LigaSure is as effective as clipping and ligation. The closure process is permanent and continuous. In case of intestinal closure, it has been considered to use LigaSure as well because similarly as blood vessel wall the intestinal wall also contains a matrix of elastin and collagen. It was aimed to research the effectiveness of the use of LigaSure in intestine closure in rats as a step to clinical studies and new technological improvements.

\section{Methods}

The study was performed by taking the permit of the ethical committee under resolution No. 2011-47 at Selcuk University Experimental Medicine Research and Application Centre.

${ }^{1}$ Konya Training and Research Hospital General Surgery Clinic, Konya Egitim ve Arastirma, Meram, Konya, Turkey, and ${ }^{2}$ Konya Training and Research Hospital Biochemistry Clinic, Konya Egitim ve Arastirma, Meram, Konya, Turkey

Address for correspondence: S. Ay, MD, Konya Training and Research Hospital General Surgery Clinic, Konya Egitim ve Arastirma Hastanesi Necip Fazil Mah. Atesbazi Sok. Meram Yeniyol, PK:42040 Meram, Konya, Turkey. Phone: +903323236709
Twenty Wistar albino rats of 250-350 gr of weight, 4-6 months of age were divided into two groups per 10 each. Food was administered ad libitum. The operation was carried out under general anaesthesia by giving intraperitoneal ketamine hydrochloride ( 80 $\mathrm{mg} / \mathrm{kg}$ ) and xylazin $(10 \mathrm{mg} / \mathrm{kg})$. The area was cleaned with povidon iodine after shaving the hair. In all rats, laparatomy was performed with an incision of $3 \mathrm{~cm}$ from the midline (Fig. 1).

The sigmoid colon was found in the rats. In Group 1, the sigmoid colon was cut from its middle and its distal was closed by $4 / 0$ silk (Dogsan, Trabzon, Türkiye) (Fig. 2). In the second group, the sigmoid colon was divided in the middle with LigaSure (ForceTriad Energy Platform, Covidien, USA) LS1200 probe, and its distal was closed with LigaSure (Fig. 3). In both groups, the proximal sigmoid colon was entered by means of colostomy with $4 / 0$ silk to the left part of the abdomen (Fig. 4). Operation time was recorded.

Postoperative rats were put into single cages and they were given standard food. Food was administered ad libitum

On the seventh day, the rats were given general anaesthesia in the same manner and the abdomen was opened in form of inverted U. Adhesives around abdomen and colostomy were photographed and recorded. A 0-4 scale was used in adhesive evaluation as follows (3):

$0=$ No adhesion available

$1=$ Thin or narrow, easily separable adhesion

$2=$ Thick adhesion limited to one area

$3=$ Adhesion spread over a thick and large area

$4=$ Thick and large adhesions, organs being adhesive to the front and/or abdominal wall 


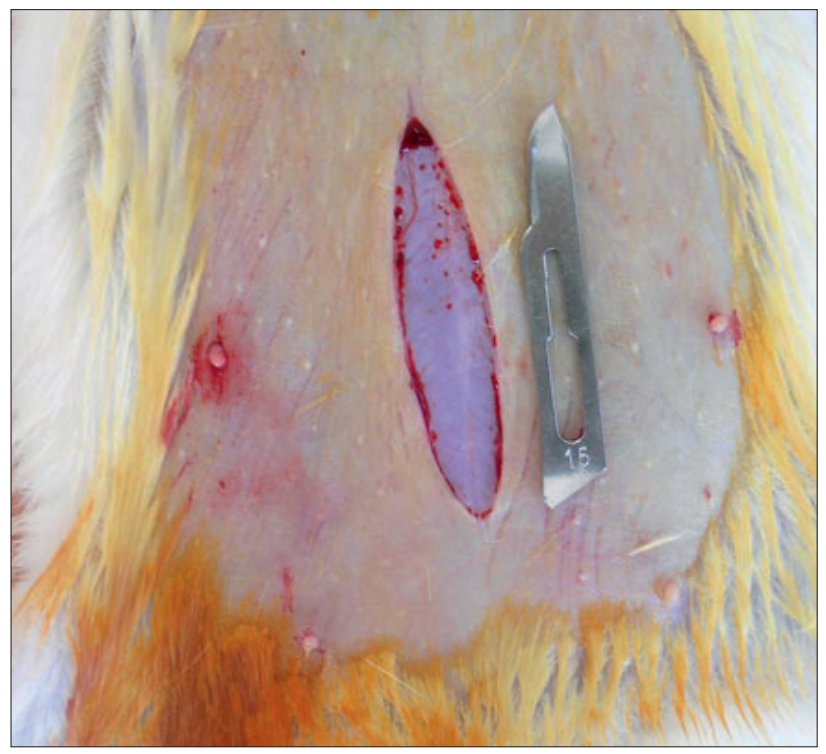

Fig. 1. Three centimetres linear incision.

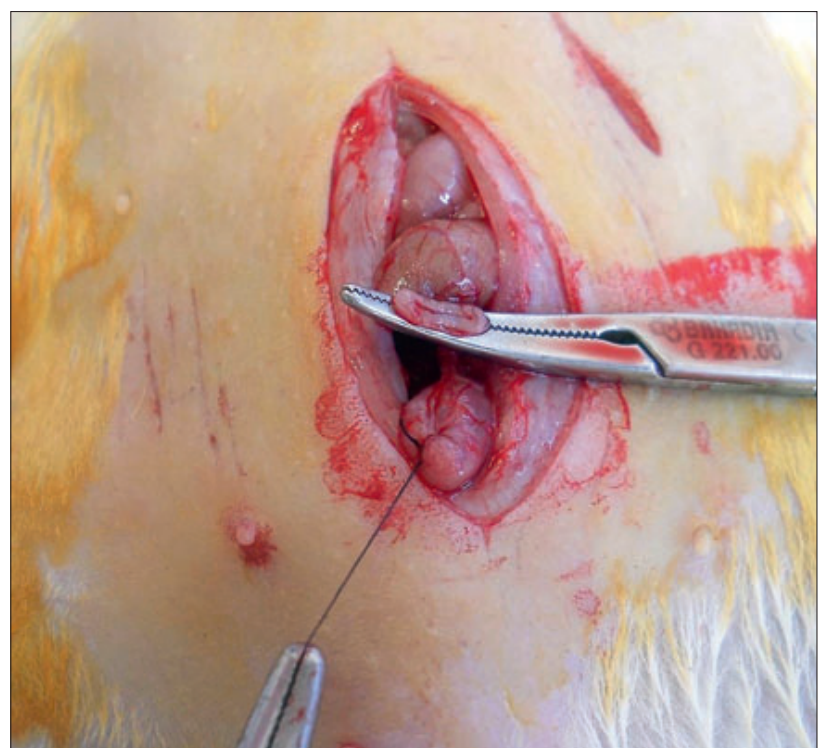

Fig. 2. Hartmann Colostomy with 4/0 Silk.

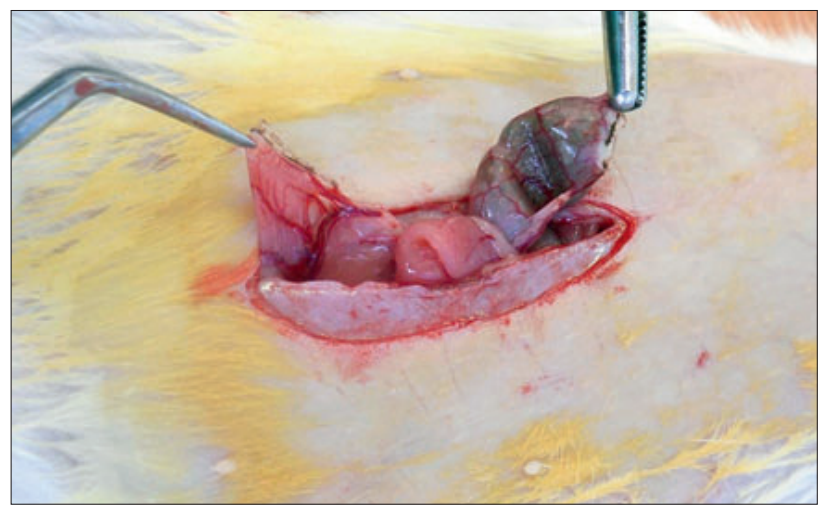

Fig. 3. Hartmann Colostomy with LigaSure.

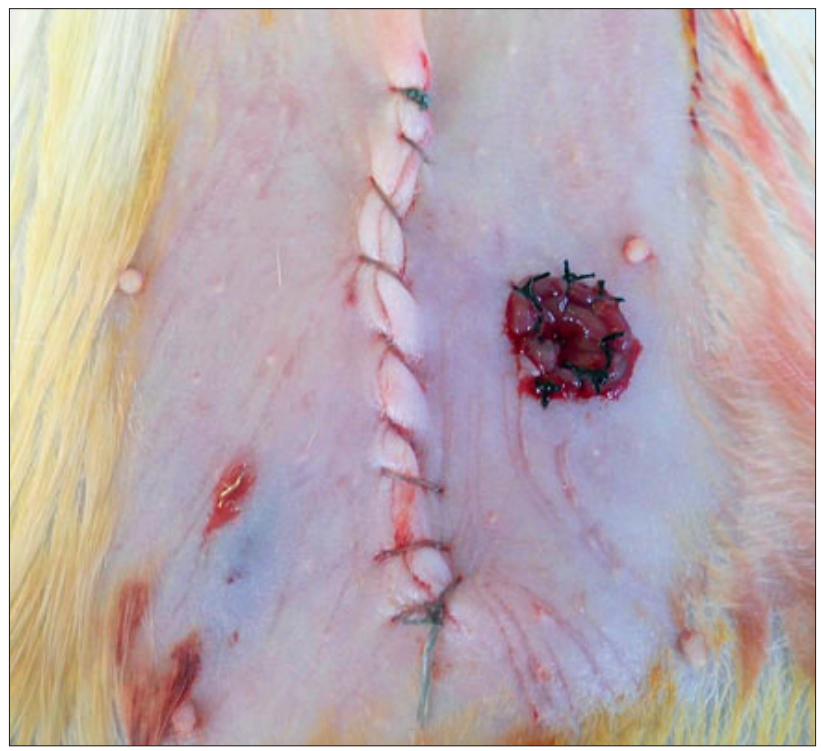

Fig. 4. Appearance of Hartmann Colostomy.

Normal saline was put into abdomen and in vivo stump explosion pressures created with Gama G-5 Heine (Germany) tension tool were measured

After measuring the explosion pressure, hydroxyproline level of the closed intestinal stump was excised for measurement. It was kept in a deep freezer (VestFrost) at 50 degrees. Samples were transported to the laboratory with special storage boxes. Tissues taken were washed and cleaned with distilled water and then weighed $1 \mathrm{~g}$ with microbalances and hydrolized at 121 degrees in $1 \mathrm{ml}$ of acidic buffer for five hours. Then, they were centrifuged at $5,000 \mathrm{rpm}$ for 20 minutes. The prepared sample was evaluated by colorimetry (photometric) (Shimadzu UV 1800 Spectrophotometer) and tissue hydroxyproline level was calculated as $\mathrm{mg} / \mathrm{L} / \mathrm{gr} /$ tissue. All biochemical measurements of samples were performed blinded to their origin.

SPSS 15.0 Windows program was used for the analysis of data. Kruskal-Wallis and Mann-Whitney U test were used to compare the intergroup data. P value being smaller than 0.05 was considered significant.

\section{Results}

In both groups, one rat was lost due to anaesthesia in postoperative early period. In Group 1 (suture group), meconium ileus developed in two rats and they were left out of the study. The study was completed with 7 rats in Group 1 and 9 rats in Group 2.

While in Group 1, the average duration of the operation was 25.7 minutes, it was 18.8 minutes in Group 2, and the difference between them was significant in favour of LigaSure $(p<0.001)$.

In both groups, no further adhesion was observed after firstdegree adhesion and there was no difference in terms of adhesion between the groups.

Stump explosion pressure was $181.4(160-190) \mathrm{mmHg}$ in average in the suture group (Group 1), and 173.3 (150-190) $\mathrm{mmHg}$ 
Tab. 1. Comparison of Groups.

\begin{tabular}{lcccc}
\hline & Adhesive Rate & Surgery Time $(\mathrm{min})$ & $\mathrm{BP}(\mathrm{mmHg})$ & $\mathrm{LH}$ \\
\hline Group 1 & 0.1 & 25.7 & 181.4 & 123.6 \\
Group 2 & 0.2 & $18.8^{*}$ & 173.3 & 123.3 \\
\hline
\end{tabular}

${ }^{*} \mathrm{p}<0.001, \mathrm{BP}-$ Bursting Pressure $(\mathrm{mmHg}), \mathrm{LH}-$ Level of Hydroxyproline (mg/ $/ \mathrm{L} / \mathrm{g} /$ tissue)

in the LigaSure group (Group 2), and the difference between them was not statistically significant.

Tissue hydroxyproline level was $123.6(13-232)$ in Group 1, and 123.3 (32-216) in Group 2, and no significant intragroup difference was determined (Tab. 1).

\section{Discussion}

LigaSure vessel closure system creates pressure with bipolar thermal energy and provides a safe and permanent closure of the vessels up to $7 \mathrm{~mm}(4,5)$. This energy destroys and unites elastin and collagen in vessel walls and creates a new closing barrier. The closure process is permanent; moreover, it was shown with experimental studies that it is as safe as clipping and ligation (2).

Vessel closure is widely used in all surgical areas mainly in general surgery. The reliability of vessel closure system with LigaSure has been proven in many clinical studies and it was shown that the duration of the operation is shortened and it provides advantage in laparoscopic surgery (6).

LigaSure system's effectiveness in other tissues apart from vessel closure was researched. Experimental studies show its effectiveness in ureter closure but low effectiveness in cystic canal closure $(7,8,9)$. Experimental studies show that the stump can be safely closed (up to $1 \mathrm{~cm}$ ) in appendectomy (10).

In LigaSure closure system, the closure is provided by destroying collagen and elastin in the vessel wall. There is plenty of collagen in the intestinal wall, too. From this point of view, a similar closure was considered to be possible also in the intestine. In their anastomosis study on four pigs, Smulders et al (11) created eight anastomoses with the prototype tool they had developed themselves by using LigaSure only (11). It was seen that the pigs were healthy for seven days. On the seventh day, they were sacrificed, opened and examined macroscopically. In the histopathological examination, on the other hand, it was shown that epithelisation and new submucosal collagen synthesis developed in the edges of anastomoses.

In their experimental study on rabbits, Sorgato et al (12) used LigaSure for intestinal closure and showed that it was effective. However, none of these studies include the measurement of anastomoses or stump explosion pressure and there are no control groups.

Unlike other studies, our study compares the closure carried out with LigaSure to that closed with suture. No leak was determined in any of the animals in distal intestinal stump. Stump explosion pressure was found to be a little low in the stump closed with LigaSure but no statistical significance was observed. On the other hand, tissue hydroxyproline level was found to be similar. The duration of the process, on the other hand, was significantly shorter in the LigaSure group. With this study, it has been shown that in experimental Hartmann type of colostomy, the stump can be closed with LigaSure as effectively as with silk.

It is considered that new horizons can be opened in laparoscopy and open surgery with the prototypes to be newly developed for the use of LigaSure closure system in anastomoses and intestinal closures. In particular, it can contribute to intestinal anastomosis creation or intestinal closure in laparoscopic surgery. If this is achieved, savings can be made as a result of shortened duration of operation and lowered expenditure on materials such as staplers.

\section{References}

1. Peterson SL, Stranahan PL, Schmaltz D, Mihaichuk C, Cosgriff N. Comparison of healing process following ligation with sutures and bipolar vessel sealing. Surg Technol Int 2002; 10: 55-60.

2. Kennedy JS, Stranahan PL, Taylor KD, Chandler JG. High burststrength, feedback-controlled bipolar vessel sealing. Surg Endosc 1998; 12: 876-878.

3. Mazuji MK, Kalambaheti K, Pawar B. Prevention of adhesions with polyvinylpyrroline. Arch Surg 1964; 89: 1011-1015.

4. Rumbaugh ML, Burba DJ, Natalini C, Hosgood G, Moore RM. Evaluation of a vessel-sealing device for small intestinal resection and anastomosis in normal horses. Vet Surg 2003; 32 (6): 574-579.

5. Campbell PA, Cresswell AB, Frank TG, Cuschieri A. Realtime thermography during energized vessel sealing and dissection. Surg Endosc 2003; 17: 1640-1645.

6. Riegler M, Cosentini E. Update on LigaSure/ Atlas vessel sealing technology in general surgery. Eur Surg 2004; 36 (2): 85-88.

7. Shamiyeh A, Vattay P, Tulipan L, Schrenk P, Bogner S, Danis J, Wayand W. Closure of the cystic duct during laparoscopic cholecystectomy with a new feedback-controlled bipolar sealing system in case of biliary obstruction-an experimental study in pigs. Hepatogastroenterology 2004; 51 (58): 931-933.

8. Matthews BD, Pratt BL, Backus CL, Kercher KW, Mostafa G, Lentzner A, Lipford EH, Sing RF, Heniford BT. Effectiveness of the ultrasonic coagulating shears, LigaSure vessel sealer, and surgical clip application in biliary surgery: a comparative analysis. Am Surg 2001; 67: 901-906.

9. Goldstein SL, Harold KL, Lentzner A. Comparison of thermal spread after ureteral ligation with the laparosonic ultrasonic shears and the LigaSure system. J Laparoendosc Adv Surg Tech 2002; 12: 61-63.

10. Elemen L, Yazir Y, Tugay M, Akay A, Aydin S, Yanar K, Ceylan S. LigaSure compared with ligatures and endoclips in experimental appendectomy: how safe is it? Pediatr Surg Int 2010; 26 (5): 539-545.

11. Smulders JF, de Hingh IH, Stavast J, Jackimowicz JJ. Exploring new technologies to facilitate laparoscopic surgery: creating intestinal anastomoses without sutures or staples, using a radio-frequency-energydriven bipolar fusion device. Surg Endosc 2007; 21 (11): 2105-2109.

12. Sorgato N, Bernante P, Pelizzo MR. Application of the LigaSure tissue sealing system to intestinal resection. Experimental and clinical trial. Ann Ital Chir. 2008 Sep-Oct;79(5):383-8. PMID: 19149369

Received May 3, 2012. Accepted August 18, 2012. 